\title{
Advances in dietary fibre characterisation. 1. Definition of dietary fibre, physiological relevance, health benefits and analytical aspects
}

\author{
Martine Champ ${ }^{1 *}$, Anna-Maria Langkilde ${ }^{2}$, Fred Brouns $^{3,4}$, Bernd Kettlitz $^{3}$ and Yves Le Bail Collet ${ }^{3}$ \\ ${ }^{1}$ Unité Fonctions Digestives et Nutrition Humaine, INRA Nantes, Rue de la Geraudière, BP 71627, 44316, \\ Nantes Cedex 3, France \\ ${ }^{2}$ Department of Clinical Nutrition, Sahlgrenska University Hospital, Göteborg University, Sweden \\ ${ }^{3}$ Cerestar Research and Development Centre, Vilvoorde, Belgium \\ ${ }^{4}$ Nutrition and Toxicology Research Institute Maastricht, Maastricht University, Netherlands
}

\begin{abstract}
Since 1953, the definition of 'dietary fibre' (DF) has evolved significantly following an international debate based on analytical progress, new nutritional and physiological knowledge and also private interests of the food industry. The overall tendency is towards an extension of the definition by including resistant starches as well as non-digestible oligosaccharides. This broadened definition is indeed based on physiological considerations as these compounds are not digested in the small intestine and become substrates for the colonic microflora, resulting in fermentation products that have a variety of local and possibly also systemic effects. A main reluctance to use this definition, however, is linked to the difficulty to quantify, with a universal method, the various compounds that fulfil the characteristics defined by this broad definition. At this point, if such a definition were adopted, there are two options, not necessarily antagonistic, which would be (1) to sum the content of NSP, resistant starches and non-digestible oligosaccharides quantified by distinct methods or (2) to use the Association of Official Analytical Chemists (AOAC) method of DF analysis (AOAC 985.29, 991.43) with complementary analyses of the different non-digestible oligosaccharides likely to be present in the food. With none of these solutions being fully satisfying from a scientific but also from a practical point of view, an innovative method has to be proposed within the next decade. The present review describes the various types of DF, effects of DF consumption on physiology and metabolism, past and current definitions, analytical aspects to measure DF and some aspects of DF claims and food labelling.
\end{abstract}

Dietary fibre: Food analysis: Food labelling: Resistant starch

\section{Introduction and history}

The term 'dietary fibre' (DF) first appeared in 1953 and referred to hemicelluloses, cellulose and lignin (Hispley, 1953). Later, Burkitt $(1971,1973)$ recommended that individuals should increase their DF intake in order to increase their stool volume and stool softness. This was based on comparisons between Africa and the UK concerning fibre intakes and disease incidence. Trowell (1972) first defined $\mathrm{DF}$ as 'the remnants of the plant cell wall that are not hydrolysed by the alimentary enzymes of man'. This definition was extended by Trowell et al. (1976) but then drastically restricted by the same group in 1978 (Trowell, 1978).

In 1981, the Association of Official Analytical Chemists
(AOAC) consensus definition referred primarily to the remnants of plant cells resistant to hydrolysis by alimentary enzymes of man but it was abandoned due to several analytical and physiological considerations.

A food industry ad hoc working group (Anonymous, 1994) proposed a definition to try to answer the need for a harmonised definition of 'fibre' in the Council Directive on Nutrition Labelling (this council was set up by the European Community in 1990) and in consideration of the first conclusions of the European Scientific Committee for Foods. It was based on both chemical and physiological considerations and included oligosaccharides and lignin.

The American Association of Cereal Chemists (AACC) proposed two definitions, in 1999 (De Vries et al. 1999)

Abbreviations: AACC, American Association of Cereal Chemists; AOAC, Association of Official Analytical Chemists; DF, dietary fibre; DP, degree of polymerisation; NDC, non-digestible carbohydrates; RS, resistant starch.

* Corresponding author: Dr Martine Champ, fax +33 2406750 12, email champ@ nantes.inra.fr 
and 2001 (American Association of Cereal Chemists, 2001), which are rather similar except that the second one included physiological aspects and does not mention the origin of the DF whereas the first one apparently limited the DF to plant sources. The authors of the AACC report in 2001 mentioned that current methodologies, AOAC official method of analysis 985.29 (Prosky et al. 1985) or AOAC 991.43 (Lee et al. 1992), will continue to be sufficient and used for most foods.

One of the most recent definitions proposed by the Food and Nutrition Board of the Institute of Medicine (Anonymous, 2001) introduced a new approach, which is to distinguish between intrinsic and intact components of plants called 'dietary fibre', and 'added fibre'; the sum of the two being called 'total fibre'.

The broad definitions of DF, including NSP (mostly of plant and algal origin), resistant starches (RS) and oligosaccharides, are approved by most scientists in the world, as shown by the recent survey of Lee \& Prosky (1995). However, there are also exceptions to this in that most of the British scientific community until recently rejected the broad DF concept and preferred the chemical definition (NSP) of Englyst and collaborators (Committee on Food Aspects, 1991). Among other 'restrictive' definitions, the Canadian definition stressed that the only origin of DF is the edible part of plants in the human diet (Health and Welfare Canada, 1985). In the same period of time, the Pilch (1987) definition was similar and specifically excluded oligosaccharides and carbohydrate polymers of less than 50 or 60 degrees of polymerisation (DP). The main reason for this exclusion was linked to DF analytical methods, which were unable to recover such components.

\section{Brief presentation of the main health benefits of dietary fibre}

Health benefits of isolated and intrinsic DF have been discussed in numerous reviews and books published during the past 10 years (for example, Carnovale et al. 1995; Cherbut et al. 1995; Mälkki \& Cummings, 1996; Guillon et al. 1998; McCleary \& Prosky, 2001) but these will not be detailed in the present review.

Initially, the interest for possible health benefits of regular DF consumption was stimulated by epidemiological studies, which linked a lack of DF to constipation, diverticulitis, cancer of the large bowel, as well as the risk of obesity, cardiovascular disease and type 2 diabetes. These chronic disorders are particularly prevalent in Western and developed countries in which refined foods and animalbased products represent a substantial share of the total food intake and in which the intake of DF is consequently rather low (Burkitt \& Trowell, 1975; Trowell \& Burkitt, 1986). Of course the aetiology of the above-mentioned diseases is multifactorial and there is no simple cause-andeffect relationship between their incidence and the intake of DF. Nonetheless, it is generally recognised that the consumption of food naturally rich in DF is beneficial to maintenance of health.

It does not seem that there is any true fibre-deficiency disorder, i.e. a disease that is induced only by low intakes of DF. A clear relationship has been found between DF intake and daily stool weight and DF has been successfully used in the treatment of constipation. However, all nonabsorbed carbohydrates can affect laxation due to osmotic effects (lactose, for instance) and/or increase the bacterial mass by serving as a substrate. It has also been shown that non-dietary inert substances such as plastic particles, which are not fermented in the colon, can increase stool output by a mechanism that does not involve increased faecal water (Lewis \& Heaton, 1997). Other large-bowel diseases such as diverticular disease and cancer are "candidate fibre-deficiency disorders'. For example, intake of insoluble fibre and particularly cellulose has been found to be inversely correlated to the risk of diverticular disease (Aldoori et al. 1998). It should also be emphasised, however, that the currently available evidence by no means supports an exclusive role of fibre in these disease conditions.

It has been claimed until recently that a high DF intake was correlated with a reduced risk of colorectal cancer and adenomas. However, since the recent study of Fuchs et al. (1999), which showed no association between the intake of DF and the risk of colorectal cancer or adenoma in women, even if the results of this study have been challenged (for example, Potter, 1999), epidemiological data have been analysed more carefully. Whole grains seem to be protective against cancer, especially gastrointestinal cancers such as gastric and colonic cancer, and hormone-dependent cancers including breast and prostate (Slavin, 2000). This protective effect is attributed to DF and other fermentable carbohydrates (oligosaccharides, RS) but also to quantitatively 'minor' substances such as antioxidants, trace minerals, phenolic compounds and phyto-oestrogens. The impact of a regular consumption of low glycaemic index carbohydrates has also recently been proposed as a beneficial effect of the intake of starchy unrefined foods such as wholegrain cereals on the aetiology of colorectal cancer. It has been proposed that this may reduce the development of insulin resistance that may occur as the result of frequent consumption of high glycaemic index carbohydrates, with or without combination with a lack of physical activity and overweight.

It seems impossible to conclude that there is a beneficial effect of all types of DF on CHD, diabetes and obesity. Indeed, the recent large epidemiological study of Willett and collaborators (Liu et al. 1999; Wolk et al. 1999) concluded that high fibre intake, particularly from cereal sources, could reduce the risk of CHD among women. Cereal-fibre consumption is also inversely correlated with risk of type 2 diabetes (non-insulin-dependent diabetes mellitus) in men and women (Salmeron et al. 1997a,b). This same correlation was not observed when total DF intake was considered. As for colon cancer, whole grains have been associated with a reduced risk of coronary and ischaemic heart disease (Jacobs et al. 1998; Liu et al. 1999) but DF cannot explain the whole effect (Anderson \& Hanna, 1999; Truswell, 2002). Similar decreases were seen with fruit and vegetable intake in the Women's Health Study (Liu et al. 2000).

Several results also support a protective role for whole grain and also for cereal fibre in the development of insulin resistance and/or type 2 diabetes (Salmeron et al. 1997a,b; Meyer et al. 2000; Pereira et al. 2002). 
Specific DF, which are often highly viscous, such as $\beta$ glucans from oats, pectins, guar gums and psyllium, have (total and LDL-) cholesterol-lowering properties that have been extensively investigated in experimental and epidemiological studies (Olson et al. 1997; Brown et al. 1999; Truswell, 1999; Anderson et al. 2000). In order to have significant effects of these isolated fibres the intake has to be very high, which is seldom the case in a normal diet. An increased intake of these DF together with other diet changes is, however, beneficial for patients with high total cholesterol values (Brown et al. 1999). The fibres mentioned above for their hypocholesterolaemic effects also exhibit a significant effect on postprandial glycaemia and insulinaemia but their impact on the risk of type 2 diabetes is not clearly proven.

RS and non-digestible oligosaccharides, which will probably be included in the definition of DF, have a number of physiological properties in common with some of the more 'classical' fibres. They are fermented in the large intestine, mostly producing significant amounts of butyrate, which is thought to be protective against colon cancer (Perrin et al. 2001). Moreover, fructo-oligosaccharides, for example, but also RS, have been identified as prebiotic agents (Cummings \& Macfarlane, 2002; Kolida et al. 2002).

Whereas dietary recommendations at the beginning of the 1990s invariably included recommendations on DF intake (World Health Organization, 1990; Committee on Food Aspects, 1991), today's recommendations focus more on the need to increase cereal foods, pulses, root crops, vegetables or fruits (Food and Agriculture Organization/ World Health Organization, 1998).

According to Cummings (1997), the health benefits of DF do not provide a distinct disease-related characteristic that can be exclusively associated with it. Constipation comes closest to fulfilling such a criterion and it is clear that some functional and physiological effects have been demonstrated with some specific fibres:

- faecal bulking or stool output (ispaghula, xanthan gum and wheat bran) (Daly et al. 1993; Marteau et al. 1994; Cummings, 1997);

- lowering of postprandial blood glucose response (highly viscous guar gum or $\beta$-glucans) (Bourdon et al. 1999);

- lowering of plasma (LDL-) cholesterol (highly viscous guar gum, $\beta$-glucans or oat bran, pectins, psyllium) (Brown et al. 1999; Anderson et al. 2000; Jenkins et al. 2002).

Some other effects have not yet been demonstrated in human subjects, such as colonic health effects related to fermentation products, although a substantial body of evidence is available from in vitro or animal models.

In many cases it seems to be that it is the DF-containing food items as a whole that have beneficial effects rather than DF per se. The content of bioactive substances in food is important together with the carbohydrate content. In epidemiological studies it is difficult to discriminate between these two categories of compounds. Long-term and epidemiological studies are lacking to confirm whether most isolated fibres may have real benefits in terms of prevention of major chronic diseases. However, enough data have been accumulated on $\beta$-glucans and psyllium to allow health claims by the US Food and Drug Administration.

\section{The main categories of definition: advantages and drawbacks}

\section{Biological definitions}

There are few definitions that are strictly based on a biological definition referring only to the origin of the DF. Indeed, the earliest formal description of DF by Trowell (1972) was both physiological and botanical: 'Dietary fibre is the proportion of food which is derived from the cellular walls of plants which is digested very poorly in human beings'. The fibrous nature of DF appeared in the term 'skeletal remains' as described in the comments of the author.

Heaton (1990) raised the concept of 'prison walls', which stresses the importance of the integrity of the cell walls for the nutritional and physiological consequences of the consumption of certain non-refined foods. This was later illustrated by the famous study of Haber et al. (1977) on apple juice, apple purée and whole apples, which demonstrated the importance of the structure of the food.

Brillouet \& Mercier (1983) suggested keeping the use of the term 'dietary fibre' for fibrous material of plant origin and to renounce the criterion of indigestibility by intestinal enzymes.

A chemical-botanical definition was supported by the Nutrition Subcommittee of the European Scientific Committee for Foods at its 90th meeting held on 16-17 September 1993. They also concluded that DF should be defined as 'non-starch polysaccharides of plant cell-wall origin'. The underlying rationale was that this corresponds to the consumer's perception of DF and accordingly will not mislead the consumer.

However, this proposal triggered strong adverse reactions, mainly from the food industry (Anonymous, 1994) resulting in the Scientific Committee for Foods at its plenary meeting of 16-17 June 1994 deciding not to give a final opinion on the definition of DF.

Some of the plant biological definitions were referring to plant cell walls. These cell walls are very diverse in structure and composition. They are principally composed of NSP. Other components of the plant cell wall represent usually no more than $10 \%$. These components are mostly undigested in the small intestine and are quantified by most gravimetric analytical methods for DF analysis. The other botanical definitions include polysaccharides, which are not necessarily located in the cell walls. It is the case, for example, for guar gums or inulin, which are storage polysaccharides for the plant.

At this point, we have to keep in mind that these plant biological definitions obviously excluded non-plant polysaccharides and especially animal, bacterial or synthetic oligoor polysaccharides. However, the main difficulty with these definitions is that no analytical methods of DF, until now, have been able to distinguish between plant and non-plant polysaccharides. Moreover, some of them have similar properties to analogous substances from plants (for example, fructo-oligosaccharides $v$. oligofructose from inulin). 


\section{Chemical definitions}

The definition proposed by Cummings (1981) was based on chemical nomenclature only and referred to "non-starch polysaccharides (NSP) and lignin'. This approach has certain merits since the chosen chemical terms have a standardised, unequivocal meaning. Moreover, NSP includes both the most abundant, intrinsic components of DF, as well as many extrinsic, non-digestible compounds: naturally occurring plant exudates (gum arabic), reserve carbohydrates (guar gum, inulin), purified pectins, as well as synthetic products such as modified celluloses and polydextrose.

According to Cummings (1997), NSP is defined as polysaccharides $(\mathrm{DP} \geq 10)$, which are non- $\alpha$-glucans that reach the human colon. Even if Englyst et al. (1982) claim that the NSP definition of DF is in keeping with the original concept of DF and that its measurement provides a reliable index of plant cell-wall material, the strict reference to plant material is impossible as no enzymic procedure can discriminate plant polysaccharides from non-plant polysaccharides.

The distinction between 'resistant starch' and 'non-starch polysaccharide' was primarily motivated by the need for labelling. It may be considered that a precise quantification of $\mathrm{RS}$ in a specific food, as at the moment of the consumption, is impossible, as RS is susceptible to increase during storage depending on the storage conditions (temperature and water content) and may also slightly decrease with reheating of the food (Englyst \& Cummings, 1987).

If the chemical nature (monomeric composition and type of linkages) is well defined, one of the problems of this definition is linked to the cut-off point of ten monomeric units, which is usually consensual but difficult to assess by simple analytical procedures.

Indeed this cut-off has been adopted because in most cases polysaccharides of $\mathrm{DP} \geq 10$ are easily isolated by precipitation in $80 \%(\mathrm{v} / \mathrm{v})$ ethanol. However, this cut-off is also quite artificial, as there are compounds of DP> 10 that are not precipitated in $80 \%$ ethanol such as some highly branched arabinans (Villettaz et al. 1981). Moreover, other compounds such as polydextrose, pyrodextrins or inulin can be classified either as oligosaccharides or polysaccharides as the range of their DP can be from around 6 to 100 . This criticism can basically be made to all definitions that exclude non-digestible oligosaccharides.

Thus, the definition of Cummings's group (Cummings, 1997 ) is rather clear from a chemical point of view. It is associated with an analytical method that is quite specific (Englyst et al. 1994). However, the classification of chemically modified polysaccharides has to be clarified, as these types of fibres have to be quantified by the analytical $\operatorname{method}(\mathrm{s})$ that are chosen to comply with the definition.

The main criticisms that are made of this chemical definition are that:

- it excludes RS and non-digestible oligosaccharides and lacks relevance from a physiological point of view. Indeed, there are very few similarities between, for example, crystalline cellulose inside a lignified cell wall and pectins of the cell wall of fresh fruits whereas there are, for instance, similarities between fermentation profiles of wheat bran, RS and fructo-oligosaccharides;
- it potentially includes non-plant polysaccharides (such as bacterial or fungal polysaccharides).

\section{Nutritional and physiological definitions}

It was first thought that DF was not digested at all in the entire intestinal tract of simple-stomached animals. However, Williams \& Olmsted (1935), and later many others, observed that there is an extensive breakdown of most cell-wall polysaccharides in the large intestine of man and animals. The non-digestibility of NSP in the small intestine of human subjects has been demonstrated in studies in ileostomy patients (Sandberg et al. 1981; Englyst \& Cummings, 1985).

NSP are unanimously considered as non-digestible in the small intestine but one should be aware of the fact that this criterion of non-digestibility is shared among many other carbohydrates. Examples are RS, oligosaccharides (from $\mathrm{DP}=3$ to $\mathrm{DP}=10$ ), most sugar alcohols (from $\mathrm{DP}=1$ ) and, in a substantial part of the global population, also lactose $(\mathrm{DP}=2)$.

Generally, the criterion of non-digestibility in the small intestine is nowadays the fundamental point of most DF definitions. In addition to this point a second criterion, usually chemical, botanical and/or analytical, is included.

This is the case with one of the earliest definitions proposed by Trowell et al. (1976), which was: "plant polysaccharides and lignin which are resistant to hydrolysis by the digestive enzymes of man'. Thus, the definition was mainly based on resistance to digestion in the upper gastrointestinal tract and included, besides constituents of the plant cell wall, fibres such as gums and pectins. The rationale for this was two-fold: (1) that isolated polysaccharides were used as model substances to study the physiological effects of DF; (2) the available analytical methods were unable to distinguish between cell-wall polysaccharides and other NSP (Asp, 1992).

Another example is the definition adopted by a food industry ad hoc working group on DF (Anonymous, 1994) to answer to the call of the Council Directive on Nutrition Labelling for Foodstuffs (90/496/EEC-article 1(4)(j); Anonymous, 1990) for a definition of DF. This definition was as follows: 'Fibre is the part of oligo- and polysaccharides and their (hydrophilic) derivatives which by human digestive enzymes cannot be decomposed to absorbable components in the upper alimentary tract. It includes lignin'. This definition is one of the broadest to have been proposed, as no criteria for the origin of the oligo- and polysaccharides are mentioned. It can also include chemically modified components. The document justifies the use of the term 'hydrophilic'. The authors of this definition wanted to exclude the compounds with fatty acid esters from the definition, as they do not have hydrophilic properties. They also wanted to keep the oligo- and polysaccharides carrying substituted sugar moieties, such as uronic acids, N-acetyl glucosamine or -galactosamine (occurring, for example, in pectin, alginates, certain plant gums, and chitin of the cell walls of fungi).

The last definition has recently been proposed by the Panel on the Definition of Dietary Fiber constituted by the Food and Nutrition Board of the US Institute of Medicine 
(Anonymous, 2001), which proposed 'two definitions to encompass current and future non-digestible carbohydrates in the food supply that are considered to be meaningful subdivisions of the potential substances that could be included.

(1)Dietary Fibre consists of non-digestible carbohydrates and lignin that are intrinsic and intact in plants.

(2) Added Fibre consists of isolated, non-digestible carbohydrates which have beneficial physiological effects in humans.

Total Fibre is the sum of Dietary Fibre and Added Fibre.'

That last definition is certainly one of the broadest definitions ever proposed as it introduces great flexibility bringing in new 'fibres' including non-digestible carbohydrates (NDC) of animal origin. The only apparent limitation (compared with several other plant biological definitions) is related to other substances associated with plant fibres, which are nevertheless often quantified as DF in gravimetric methods.

The physiological definition, when based on a criterion of 'non-digestibility' in the small intestine, is undoubtedly not precise. Indeed this criterion may vary from one subject to another, as the digestibility in the upper part of the gastrointestinal tract is quite variable between subjects and depends also on the chewing efficiency and gastrointestinal transit time. Moreover, it is quite difficult to obtain an analytical method that would reflect an in vivo digestion and which could be valid for any type of substrate. However, the main advantage of a physiological definition is that it refers to a criterion that is important from a nutritional point of view.

Although DF is generally characterised by its nondigestibility in the small intestine, different categories of DF have different physiological effects. As a consequence, it may be considered that a DF definition cannot be of a generalised nature with regard to specific beneficial effects on health that have been observed for certain sub-categories. The recent definition cited earlier (Anonymous, 2001) mentioned that the 'added fibres' must have beneficial physiological effects in human subjects.

Earlier, Asp (1995) suggested the following definition of DF for labelling purposes:

'Dietary fibre means indigestible material as measured with a standard method, such as an enzymatic, gravimetric AOAC method, and with addition, when relevant, of carbohydrates fulfilling the following criteria:

- indigestible in the human small intestine

- one or several physiological effects typical for dietary fibre

- measurable in the food in question with a reasonably simple method.'

However, none of the available methods (including the mentioned AOAC method) is able to quantify all types of DF as defined by Asp (1995).

The definition of DF recently proposed by the American Association of Cereal Chemists (2001) also considers physiological effects of DF but is more precise than the others. It is as follows:
'Dietary fibre is the edible parts or analogous carbohydrates that are resistant to digestion and absorption in the small intestine with complete or partial fermentation in the large intestine. Dietary fibre includes polysaccharides, oligosaccharides, lignin, and associated plant substances. Dietary fibres promote beneficial physiological effects including laxation, and/or blood cholesterol attenuation, and/or blood glucose attenuation'.

It seems obvious that at least the scientific community and most national and international authorities are now proposing definitions, including the mentioning of beneficial physiological effects. This precaution aims to eliminate from the DF concept several molecules or extracts that may have techno-functional properties but no interest for health. It should thus avoid misleading consumers.

\section{Analytical definition}

For food labelling and inspection purposes, an analytical definition is likely to be the simplest and most appropriate one. Indeed if the 'official method' is sufficiently reproducible and simple, there will be no possibility for dispute. The risk is that new compounds, which might have valuable properties for health and are similar in many aspects to 'dietary fibre', may not be quantified by the 'official method'. One could imagine that the 'official method' will constantly be modified to include these new beneficial compounds. If it is the case that this is not done, no new products can be authorised to be labelled as 'dietary fibre'.

All recent analytical methods include an enzymic step, which mimics digestion in the upper alimentary tract. 'Non-digestibility' is therefore also included as a criterion in analytical definitions of DF.

In the USA and some other countries AOAC method 985.29 for Total Dietary Fibre Determination in Foods (Prosky et al. 1985) has become the de facto definition of DF for labelling, in the absence of regulatory definition. This method is mentioned in the definition of Asp (1995) and is artfully implied in the definition of the panel constituted by the Food and Nutrition Board of the Institute of Medicine (Anonymous, 2001), which introduced the term 'total fibre' (sum of 'dietary fibre' and 'added fibre') that is very close to the title 'total dietary fibre' of the AOAC method (Prosky et al. 1985). The use of this method raises a number of questions, which will be addressed below.

The definition proposed by Englyst \& Cummings (DF = $\mathrm{NSP}+$ lignin) is based on the analytical procedure proposed by the same group. The advantages and drawbacks will also be discussed later.

\section{General discussion on the definitions}

From the previous sections it generally appears that DF can be defined as part of the plant, as chemical substances, by its indigestibility in the small intestine and/or by its beneficial digestive and physiological effects, as well as by its final metabolic fate.

Most of the recent definitions are based on more than one characteristic. They can thus include chemical, botani- 
cal or analytical considerations associated with a criterion of non-digestibility in the small intestine and/or beneficial health effects.

Most scientists and specialists in the food industry tend to enlarge the definition to include oligosaccharides not digested in the small intestine, as well as RS.

The main argument in favour of the broadest definition is that there are, for example, more similarities (in physicochemical and/or physiological characteristics) between oligosaccharides, RS and highly fermentable NSP than amongst the whole NSP category.

Even though the indigestibility in the small intestine of DF is no longer discussed, there is still a debate on the need to include physiological considerations in the definition of DF. Indeed several opponents to this introduction stated that such considerations are not based on sufficiently clear evidence except perhaps for prevention of constipation, which would be very restrictive.

The major question is then raised whether a necessary proven beneficial effect of DF should be a prerequisite for the definition or whether physiologically 'neutral' compounds such as some techno-functional polysaccharides should be included in the definition. If the first solution were to be adopted, considerations of the physiological impact of DF, which might be more relevant for the consumer, should be added as it is in the definition proposed by Asp (1995) and the American Association of Cereal Chemists (2001).

The inclusion of some associated substances to the cell wall, such as lignin or cutin, is not systematic and the exclusion of chemically modified compounds is rarely mentioned in the definitions.

The problem is more acute when the inclusion in the definition of non-plant oligo- or polysaccharides is considered. Indeed, plant oligo- and polysaccharides cannot be distinguished from non-plant carbohydrates of similar composition.

The exclusion of non-plant oligo- and polysaccharides would exclude animal polysaccharides, which might be appropriate to avoid confusion among consumers, but also synthetic oligosaccharides such as fructo-oligosaccharides, which have the same physiological properties as other prebiotic compounds of plant origin.

Another important question has been raised by Trowell (1978), who proposed that DF added to food (for instance wheat bran) should not be regarded as 'dietary fibre' as it would not convey all the beneficial physiological effects of a diet with a naturally high DF content. This concept was not pursued until very recently, however, due to the problem of differentiating between 'extrinsic', i.e. added, and 'intrinsic', i.e. naturally present DF by analytical means. The debate has been reopened following the results published by Willett and collaborators (Liu et al. 1999) on whole grains especially. Their observations are still very controversial but they are considered in the recent definition proposed by the US Institute of Medicine (Anonymous, 2001) with the distinction between 'dietary fibre', intrinsic and intact in plants, and 'added fibre'.

\section{From the definition to the nutritional claim}

The exact definition of DF is of substantial importance for the global food market and its control authorities, as the product labelling concerning DF will have to be validated by an analytical method that properly quantifies all the possible fibre components included in the definition. Such labelling is required to inform the consumer that the product contains a certain quantity of DF, which is supposed to be good for health according to consumers' current understanding.

If the legal definition is to include physiological considerations, we might wonder if it will not be used as a claim and what degree of evidence will be needed to use the term 'dietary fibre' for labelling purposes. The use of claims mentioned on the packaging of food products should indeed be distinguished from the definition as the claim is referring to the exact constituents (origin, structure, etc) of the food. According to the United States Food and Drug Administration (1999), claims can be put into three categories: nutrient content claims; relative (or comparative) claims; health claims.

Some health claims have recently been authorised in the USA, by the United States Food and Drug Administration (1999), for some of these fibres or fibre sources. Psyllium has been approved for its effect of reducing cardiovascular risk factors and sources of $\beta$-glucans (oat-bran soluble fibre), such as oat bran or flour, have been approved for their effects of lowering LDL-cholesterol. Furthermore, foods that are rich in fibre (when expressed in $\mathrm{g}$ DF/100 $\mathrm{kJ}$ ), like most whole cereal products, fruits and vegetables, may be marketed with a health claim as such foods have been shown to reduce the risk of some cancers that are recognised as being multi-factorial diseases, in which the daily diet plays a significant role.

In Europe, legislation regarding health claims and functional foods is not yet harmonised but countries such as France recently authorised the claim 'bifidogenic effect' for oligosaccharides and fructo-oligosaccharides. This is not yet the case for plant polysaccharides mentioned earlier such as oat $\beta$-glucans or psyllium.

\section{The different categories of analytical methods: advantages and drawbacks}

Table 1 summarises the main methods of DF analysis.

\section{Non-enzymic-gravimetric methods}

This category of methods includes the so-called Weende method (Association of Official Analytical Chemists, 1980), which quantifies the 'crude fibre' (cellulose + lignin) and the 'Van-Soest method' (Van-Soest \& Wine, 1967), which quantifies successively the neutral-detergent fibre (cellulose + hemicelluloses + lignin) and the acid-detergent fibre (cellulose + lignin). Although these methods are still used for the purpose of characterising animal feeds, it is admitted that they are not appropriate for the purpose of food analysis, as they do not quantify both soluble DF and insoluble fibre.

\section{Enzymic-gravimetric methods}

In the early 1980s, an enzymic-gravimetric method was developed in which the sum of soluble polysaccharides, 
Table 1. Main methods of dietary fibre analysis

\begin{tabular}{|c|c|c|c|c|}
\hline Reference & Name & Type & Measures & Main concerns \\
\hline $\begin{array}{l}\text { Association of Official } \\
\text { Analytical Chemists (1980) }\end{array}$ & $\begin{array}{l}\text { Crude fibre or } \\
\text { 'Weende' method }\end{array}$ & Gravimetric & $\begin{array}{l}\text { Most of the cellulose } \\
\text { and lignin }\end{array}$ & Only adapted to forages \\
\hline Van-Soest \& Wine (1967) & Van Soest method & Gravimetric & $\begin{array}{l}\text { Most of the cellulose, } \\
\text { acid insoluble } \\
\text { hemicellulose and lignin }\end{array}$ & Mainly adapted to forages \\
\hline Prosky et al. (1985) & $\begin{array}{l}\text { Total dietary fibre; } \\
\text { AOAC } 985.29\end{array}$ & Enzymic-gravimetric & $\begin{array}{l}\text { Soluble and insoluble } \\
\text { polysaccharides and } \\
\text { lignin }\end{array}$ & $\begin{array}{l}\text { Quantify only a portion of } \\
\text { resistant starch (part of } \\
\text { RS3) } \\
\text { Inulin or polydextrose are } \\
\text { not quantified }\end{array}$ \\
\hline Englyst \& Hudson (1987) & Englyst method & $\begin{array}{l}\text { Enzymic-chemical or } \\
\text { GLC or HPLC }\end{array}$ & NSP & Lack of reproducibility (?) \\
\hline Theander et al. (1994) & Uppsala method & Enzymic-chemical & $\begin{array}{l}\text { Neutral and uronic } \\
\text { residues and Klason } \\
\text { lignin }\end{array}$ & Few users of the method \\
\hline McCleary \& Codd (1991) & $\begin{array}{l}\text { AOAC 995.16; } \\
\text { AACC } 32-23\end{array}$ & Enzymic & $\beta$-Glucans & \\
\hline Englyst et al. (1992) & Resistant starch & Enzymic & Resistant starch & $\begin{array}{l}\text { Lack of reproducibility (?) } \\
\text { but validated with in vivo } \\
\text { data }\end{array}$ \\
\hline $\begin{array}{l}\text { McCleary \& Monaghan } \\
(2002)\end{array}$ & $\begin{array}{l}\text { AOAC 2002-02; } \\
\text { AACC } 37.42\end{array}$ & Enzymic & Resistant starch & Consistent with in vivo data \\
\hline Hoebregs (1997) & AOAC 997.08 & $\begin{array}{l}\text { Enzymic and ion- } \\
\text { exchange } \\
\text { chromatography }\end{array}$ & $\begin{array}{l}\text { Oligofructan, inulin, } \\
\text { fructo-oligosaccharides }\end{array}$ & \\
\hline Ouarne et al. (1999) & & $\begin{array}{l}\text { lon-exchange } \\
\text { chromatography }\end{array}$ & $\begin{array}{l}\text { Oligofructan, inulin, } \\
\text { fructo-oligosaccharides }\end{array}$ & \\
\hline Craig et al. (2001) & AOAC 2000.11 & HPLC & Polydextrose & \\
\hline
\end{tabular}

AOAC, Association of Official Analytical Chemists; AACC, American Association of Cereal Chemists.

insoluble polysaccharides and lignin were quantified as 'total dietary fibre' (AOAC 45.4.07; Association of Official Analytical Chemists International, 1995). The procedure was later extended to the determination of insoluble and soluble dietary fibre (AOAC 32.1.16 and 45.4.08 respectively; Association of Official Analytical Chemists International, 1995). Finally the phosphate buffer used in these methods was substituted by a 2-(N-morpholino) ethanesulfonic acid-tris (hydroxymethyl) aminomethane buffer. All these methods use the same three enzymes (heat stable $\alpha$-amylase, protease and amyloglucosidase) (Lee et al. 1992).

In these methods, protein and starch are digested enzymically. The starch digestion step requires the use of a heat-resistant $\alpha$-amylase and amyloglucosidase. Addition of ethanol to the mixture results in precipitation of moderately soluble NSP. The insoluble and ethanol-precipitated material is separated from the soluble fraction by filtration and quantified gravimetrically. DF recovered with this procedure includes cellulose, hemicellulose, pectins, some other NSP, lignin and a portion of RS. Soluble and insoluble DF may be measured separately (Lee et al. 1992). Some indigestible polysaccharides that are soluble in 78-80\% $(\mathrm{v} / \mathrm{v})$ ethanol such as inulin and polydextrose are not detected by this method. However new procedures have been proposed to quantify most of these compounds:

- $\beta$-Glucans (AOAC 995.16; AACC method 32-23; McCleary \& Codd, 1991);
- RS (Englyst et al. 1992, 1996; Goni et al. 1996; Champ et al. 1999 and AOAC 2002.02 and AACC 37.42 (McCleary \& Monaghan, 2002));

- Oligofructan, inulin, fructo-oligosaccharides (AOAC 997.08 (Hoebregs, 1997) and 999.03 (McCleary et al. 2000)). The AOAC DF method (985.29; Prosky et al. 1985) should indeed be modified when inulin is present in food as some inulin can precipitate with $80 \%(\mathrm{v} / \mathrm{v})$ ethanol. Coussement (1999), Dysseler et al. (1999) and Ouarne et al. (1999) simultaneously proposed methods to quantify this category of compounds;

- Polydextrose is not quantitatively measured with AOAC method 985.29 (Prosky et al. 1985) because it is not completely precipitated with $80 \%$ (v/v) ethanol. An HPLC method to quantify polydextrose in food has been adopted as first action and assigned AOAC number 2000.11 (Craig et al. 2001).

Thus, one should emphasise that, although specific methods are available to quantify compounds that are not properly (or not at all) detected by the AOAC-approved DF procedure, none of these methods is able to quantify simultaneously all the non-digestible oligosaccharides. This is an important point since these would be included in the definition of DF if the broadest definition were adopted.

The AOAC method for analysis of DF in foods (AOAC 985.29 (Prosky et al. 1985) and 991.43 (Lee et al. 1992)) measures cell-wall polysaccharides, part of the retrograded amylose-type RS, gums and mucilages, and lignin. It is 
therefore closer to the definition based on small-intestinal digestibility than the Englyst method, which was designed only to measure NSP. However, this AOAC method quantifies only a part of the RS within the DF fraction. Accordingly, for the residual starch fraction to be quantified in the DF residue, another type of quantification for RS should be performed by using a different method. Another problem of this method, which is also common to most other analytical methods that quantify 'dietary fibre', is the quite arbitrary elimination (in terms of the DP) of DF as defined from a physiological point of view. This happens because the method separates low-molecular weight carbohydrates from polysaccharides on the basis of their solubility in $80 \%(\mathrm{v} / \mathrm{v})$ ethanol. Accordingly, separate analyses have to be made for oligosaccharides, inulin, and polydextrose when NDC have to be analysed in a food, but none of the additional methods are able to quantify all the oligosaccharides in a single run. The main advantage of the AOAC method may be its good reproducibility (relative to the Englyst methods) but that has not been confirmed in the certification study published in 1996 by the European Commission (Pendlington et al. 1996) in which twentyseven laboratories took part.

\section{Enzymic-chemical methods}

This section on enzymic-chemical methods also includes enzymic colorimetric and enzymic-GLC-HPLC methods.

The 'Uppsala method' (Theander et al. 1995) concerns the quantification of neutral and uronic acid residues and Klason lignin (45.4.11.AOAC). After removal of the starch, soluble fibre is precipitated in $80 \%$ (v/v) ethanol. Soluble and insoluble fibres are hydrolysed with sulphuric acid. Neutral sugars are then quantified by GLC whereas uronic acids are determined by a colorimetric method. Finally, Klason lignin is quantified gravimetrically.

The Englyst method (Englyst \& Hudson, 1987; Englyst \& Cummings, 1988) quantifies NSP. Starch is first solubilised with dimethyl sulfoxide and then hydrolysed enzymically. After addition of ethanol, NSP is measured in the insoluble, ethanol-precipitated fraction. For quantification starch and NSP are subsequently hydrolysed (acid hydrolysis) and the sugars (neutral sugars and uronic acids) are quantified by colorimetry (acidic sugars and neutral sugars), GLC (individual neutral sugars) or HPLC. The Englyst method yields a value for total and, if required, for soluble and insoluble NSP. A small modification allows cellulose to be measured separately.

In contrast to the AOAC method, starch is (theoretically) completely eliminated from the sample by the solubilisation with dimethyl sulfoxide and the further enzymic degradation procedure. It is possible to quantify RS separately by other methods including one proposed by the same group (Englyst et al. 1992) and by AOAC 2002.02 and AACC 37.42 (McCleary \& Monaghan, 2002).

The main advantage of the NSP analytical method (Englyst method) is that it clearly identifies the compounds that are susceptible to be included in NSP. It offers the possibility to quantify separately the RS and non-digestible oligosaccharides without major interference between methods. Its main drawback seems to be its lack of repro- ducibility as well as that its use has mostly been restricted to the UK.

\section{Comparisons of methods presented earlier through inter- laboratory studies and general discussion on analytical methods}

Most comparative and collaborative studies have examined the Englyst procedure and/or the enzymic-gravimetric AOAC method for their performance in terms of practical feasibility for routine measurements as well as intra- and inter-laboratory variance (Asp \& Johansson, 1981; Cummings et al. 1985; Mongeau \& Brassard, 1986, 1990; Englyst et al. 1987; Schweizer et al. 1988; Wood et al. 1993; Pendlington et al. 1996).

These studies have led to the following conclusions:

(1)The AOAC method yields somewhat more reproducible results than Englyst methods but both methods can be used for routine food analyses (Asp, 1992). However, results published in 1996 in a document edited by the European Commission (Pendlington et al. 1996) do not confirm the better reproducibility of the AOAC methods (985.29 and 991.43) over Englyst methods (GC or colorimetry) (Englyst et al. 1994);

(2) The AOAC method gives substantially higher values for insoluble and total DF and lower values for soluble DF than the Englyst method results from a comparative study involving thirty-one European and North American laboratories with an average of twelve foods analysed (Lee \& Prosky, 1992). This observation has been confirmed (Pendlington et al. 1996);

(3) The AOAC procedure gives a higher total DF value for some starchy foods such as potato, bread, beans and cornflakes because some RS is also recovered as DF;

(4) The AOAC procedure gives a higher DF value for some foods such as banana and coconut because of the loss of some NSP in the Englyst procedure due to partial degradation and solubilisation during the dimethyl sulfoxide treatment.

Most of the methods allow the quantification of a large spectrum of compounds, which are not digested by protease and $\alpha$-amylase.

The questions that remain unresolved are the following:

- If the definition of DF includes compounds such as nondigestible oligosaccharides and RS, should the 'official' analytical method(s) be adapted to be able to quantify them systematically?

- Should the analytical method be able to detect the origin of the DF if non-plant poly- and oligosaccharides are excluded from the definition?

Our answer is a clear 'yes'; the 'official' analytical method should provide the DF content in accordance with the definition. However, none of the methodologies available are able to provide an optimal analytical method that would quantify the DF if: (1) there is a restriction in the origin of the DF (for instance, exclusion of compounds of animal origin); (2) the definition is not restricted to NSP, which is highly probable. 
A temporary solution will then have to be considered, which will need to be compatible with the legal definition that is to be adopted.

\section{Towards a consensus}

Lee \& Prosky (1995) conducted an international survey of 147 professionals involved in DF research. Of the scientists, $43 \%$ defined DF as polysaccharides and lignin that are not hydrolysed by human alimentary enzymes. This certainly was not the last discussion on what the ideal DF definition should be. Three facts are of importance in this respect: (1) the progressive development of a functional foods market; (2) the related recognition that DF sub-categories, such as some specific non-digestible oligosaccharides and RS, may have health maintenance-supporting effects has led to the reconsideration that the analytical method that is used to measure DF appropriately, accordingly to its definition, is of significant importance; (3) currently, these sub-categories are not measured by the approved AOAC analytical method for DF.

\section{Conclusion}

How is a consensus for the purpose of fibre-related health claims and for appropriate food labelling to be achieved? For appropriate food labelling, that means 'on package declaration of contents', a definition of DF must be related to an analytical method that is suitable to be carried out in an ordinary food analysis laboratory. In this respect it seems appropriate to distinguish in the first instance between two fractions of carbohydrates in the food, i.e. digestible and indigestible carbohydrates, or available and unavailable carbohydrates. The term 'dietary fibre' is generally conceived as more or less synonymous with indigestible or unavailable carbohydrates and, due to the popularity of this term in recent years, it may be considered as an appropriate one to denote carbohydrates that are not digested in the small intestine. However we would prefer the term 'indigestible carbohydrates' or 'non-digestible carbohydrates', as this term is scientifically correct and will be less confusing for the consumer, who may perceive DF as brans and 'fibrous' components of vegetables. We do agree however with the argument that the term indigestible carbohydrates' has a negative connotation. Nevertheless, by providing good information to the consumer relative to these compounds these new terms ('indigestible carbohydrates' or 'non-digestible carbohydrates') could definitely be clarified.

We also propose a broad definition that is close to that proposed by Asp (1995). 'Dietary fibre (or NDC) means non-digestible material, which is (mainly) composed of polymeric and oligomeric carbohydrates (may include minor compounds naturally associated to polysaccharides in the cell walls if the term dietary fibre is maintained) and fulfilling the following criteria:

(1) indigestible in the human small intestine; (2) one or several physiological effects typical for dietary fibre; (3) measurable in the food with a reasonably simple methodology.'
The analytical method of choice has to be able to quantify all DF as described by the definition. In case some components are not quantified by the 'main' method (AOAC total dietary fibre, for instance), these components could be quantified by specific methods providing that these components are identified on the labelling and that there is no overlap between the methods. Alternatively it can be decided that DF is the sum of NSP + RS + nondigestible oligosaccharides and that the analysis of DF would require three (or more) analytical methods to quantify the three categories of compounds. In that case, it will be necessary to make sure that these methods will not overlap with regard to the quantification of some of the components. The advantage of the latter solution (three methods) is that it gives the possibility to indicate, on the label of the food, a more precise composition of NDC.

With regard to quantification one should be aware of the fact that there is a clear overlap between the content of DF as measured by the AOAC method and that of RS. Accordingly, the official AOAC method should be modified to avoid this overlap. In the meantime, it should be acceptable for food labelling to:

- use the AOAC method as the unique method for the quantification of the DF content in foods that are poor in starch (and consequently do not contain significant amounts of RS) and oligosaccharides;

- accept that food manufacturers may declare the DF content of foods that contain a significant amount of RS on the basis of both a specific RS method and of the AOAC method, with the prerequisite that the protocol for quantification is adapted to obtain a correct DF by the AOAC method;

- use another DF method to quantify NSP (for example, the Englyst method);

- use specific methods to quantify non-digestible oligosaccharides.

In conclusion we recommend the adoption of the definition given earlier for the allowance of claims that are related to the amount of DF in the food.

\section{References}

Aldoori WH, Giovannucci EL, Rockett HR, Sampson L, Rimm EB \& Willett WC (1998) A prospective study of dietary fiber types and symptomatic diverticular disease in men. Journal of Nutrition 128, 714-719.

American Association of Cereal Chemists (2001) The definition of dietary fiber. Report of the Dietary Fiber Definition Committee to the Board of Directors of the American Association of Cereal Chemists. Cereal Foods World 46, 112-126. http:// www.scisoc.org/aacc/DietaryFiber/report.html

Anderson JW, Allgood LD, Lawrence A, Altringer LA, Jerdack GR, Hengehold DA \& Morel JG (2000) Cholesterol-lowering effects of psyllium intake adjunctive to diet therapy in men and women with hypercholesterolemia: meta-analysis of 8 controlled trials. American Journal of Clinical Nutrition 71, 472-479.

Anderson JW \& Hanna TJ (1999) Whole grains and protection against coronary heart disease: what are the active components and mechanisms? American Journal of Clinical Nutrition 70, 307-308. 
Anderson JW, Hanna TJ, Peng X \& Kryscio RJ (2000) Whole grain foods and heart disease risk. Journal of the American College of Nutrition 19, Suppl. 3, 291S-299S.

Anonymous (1990) Council Directive 90/496/EEC on Nutrition Labelling for Foodstuffs. EC Official Journal.

Anonymous (1994) Defining dietary fibre for nutrition labelling purposes. Report from Food industry ad hoc working group on dietary fibre. International Food Ingredients 1, 46-49.

Anonymous (2001) Dietary Reference Intakes - Proposed Definition of Dietary Fiber. A report of the panel on the definition of dietary fiber and the standing committee on the scientific evaluation of dietary references intakes (Food and Nutrition Board, Institute of Medicine). Washington, DC: National Academy Press.

Asp NG (1992) Resistant starch - Proceedings from the second plenary meeting of EURESTA: European FLAIR Concerted Action No. 11 on physiological implications of the consumption of resistant starch in man. Preface. European Journal of Clinical Nutrition 46, Suppl. 2, S1.

Asp NG (1995) Dietary fibre analysis - an overview. European Journal of Clinical Nutrition 49, S42-S47.

Asp NG \& Johansson CG (1981) Techniques for measuring dietary fiber. Principal aims of methods and a comparison of results obtained by different techniques. In The Analysis of Dietary Fiber in Food, pp. 173-189 [WPT James and O Theander, editors]. New York: Marcel Dekker.

Association of Official Analytical Chemists (1980) Official Methods of Analysis, 11th ed., p. 129 [W Horwitz, editor]. Washington, DC: AOAC.

Association of Official Analytical Chemists International (1995) Total, soluble and insoluble dietary fiber in foods. AOAC official method 991.43. In Official Methods of Analysis, 16th ed. Washington, DC: AOAC.

Bourdon I, Yokoyama W, Davis P, Hudson C, Backus R, Richter D, Knuckles B \& Schneeman B (1999) Postprandial lipid, glucose, insulin, and cholecystokinin responses in men fed barley pasta enriched with $\beta$-glucan. American Journal of Clinical Nutrition 69, 55-63.

Brillouet JM \& Mercier C (1983) Fibres alimentaires en nutrition humaine (Dietary fibres in human nutrition). Cahiers de Nutrition et de Diététique 18, 65-69.

Brown L, Rosner B, Willett WW \& Sacks FM (1999) Cholesterollowering effects of dietary fiber: a meta-analysis. American Journal of Clinical Nutrition 69, 30-42.

Burkitt DP (1971) Epidemiology of cancer of colon and rectum. Cancer 28, 3-13.

Burkitt DP (1973) The role of refined carbohydrate in large bowel behaviour and disease. Plant Foods for Man 1, 5-9.

Burkitt DP \& Trowell HC (editors) (1975) Refined Carbohydrate Foods and Disease - Some Implications of Dietary Fibre. London: Academic Press.

Carnovale E, Tomassi G \& Cummings JH (1995) Topics in Dietary Fibre Research. Proceedings of an International Symposium within the framework of the COST 92 Programme, Rome, Italy, 5-7 May 1992. European Journal of Clinical Nutrition 49, Suppl. 3, S1-S327.

Champ M, Martin L, Noah L \& Gratas M (1999) Analytical methods for resistant starch. In Complex Carbohydrates in Foods, pp. 169-187 [SS Cho, L Prosky and M Dreher, editors]. New York: Marcel Dekker Inc.

Cherbut C, Barry JL, Lairon D \& Durand M (editor) (1995) Dietary fibre - Mechanisms of action in human physiology and metabolism. Paris, France: John Libbey Eurotext.

Committee on Food Aspects (1991) Non-starch polysaccharides. In Dietary Reference Values for Energy and Nutrients for the United Kingdom, pp. 61-71. London: HM Stationery Office.

Coussement P (1999) Inulin and oligofructose as dietary fiber: analytical, nutritional and legal aspects. In Complex
Carbohydrates in Foods, pp. 203-212 [SS Cho, L Prosky and M Dreher, editors]. New York: Marcel Dekker Inc.

Craig SA, Holden JF \& Khaled MY (2001) Determination of polydextrose in foods by ion chromatography: Collaborative study. Journal of AOAC International 84, 472-478.

Cummings JH (1981) Dietary fibre. British Medical Bulletin 37, 65-70.

Cummings JH (1997) The Large Intestine in Nutrition and Disease. Brussels, Belgium: Institut Danone. http://www. danoneinstitute.be/communication/pdf/mono06/mono6full.pdf

Cummings JH, Englyst HN \& Wood R (1985) Determination of dietary fibre in cereals and cereal products - collaborative trials. Part I: Initial trial. Journal of the Association of Public Analysts 23, 1-35.

Cummings JH \& Macfarlane GT (2002) Gastrointestinal effects of prebiotics. British Journal of Nutrition 87, Suppl. 2, S193-S197.

Daly J, Tomlin J \& Read NW (1993) The effect of feeding xanthan gum on colonic function in man: correlation with in vitro determinants of bacterial breakdown. British Journal of Nutrition 69, 897-902.

DeVries JW, Prosky L, Li B \& Cho S (1999) A historical perspective on defining dietary fibre. Cereal Foods World 44, 367-369.

Dysseler P, Hoffem D, Fockedey J, Quemener B, Thibault J-F \& Coussement P (1999) Determination of inulin and oligofructose in food products (modified AOAC dietary fiber method). In Complex Carbohydrates in Foods, pp. 213-227 [SS Cho, L Prosky and M Dreher, editors]. New York: Marcel Dekker Inc.

Englyst HN \& Cummings JH (1985) Digestion of the polysaccharides of some cereal foods in the human small intestine. American Journal of Clinical Nutrition 42, 778-787.

Englyst HN \& Cummings JH (1987) Digestion of the polysaccharides of potato in the human small intestine. American Journal of Clinical Nutrition 45, 423-431.

Englyst HN \& Cummings JH (1988) Improved method for measurement of dietary fiber as non-starch polysaccharides in plant foods. Journal of AOAC International 71, 808-814.

Englyst HN, Cummings JH \& Wood R (1987) Determination of dietary fibre in cereals and cereal products - collaborative trials. Part II: Study of the modified Englyst procedure. Journal of the Association of Public Analysts 25, 59-71.

Englyst HN \& Hudson GJ (1987) Colorimetric method for routine measurement of dietary fiber as non-starch polysaccharides. A comparison with gas-liquid chromatography. Food Chemistry 24, 63-76.

Englyst HN, Kingman SM \& Cummings JH (1992) Classification and measurement of nutritionally starch fractions. European Journal of Clinical Nutrition 46, Suppl. 2, S33-S50.

Englyst HN, Kingman SM, Hudson GJ \& Cummings JH (1996) Measurement of resistant starch in vitro and in vivo. British Journal of Nutrition 75, 749-755.

Englyst HN, Quigley ME \& Hudson GJ (1994) Determination of dietary fibre as non-starch polysaccharides with gas-liquid chromatographic, high-performance liquid chromatographic or spectrophotometric measurement of constituent sugars. Analyst 11, 1497-1509.

Englyst HN, Wiggins HS \& Cummings JH (1982) Determination of the non-starch polysaccharides in plant foods by gas-liquid chromatography of constituent sugars as alditol acetates. Analyst 107, 307-318.

Food and Agriculture Organization/World Health Organization (1998) Carbohydrates in Human Nutrition. FAO food and nutrition paper, no. 66. Report of a Joint FAO/WHO Expert Consultation, Rome, April 1997. Rome: FAO.

Fuchs CS, Giovannucci EL, Colditz GA, Hunter DJ, Stampfer MJ, Rosner B, Speizer FE \& Willett WC (1999) Dietary fiber and the risk of colorectal cancer and adenoma in women. New England Journal of Medicine 340, 169-176. 
Goni I, Manas E, Garcia-Diz L \& Saura-Calixto F (1996) Analysis of resistant starch: a method for food and food products. Food Chemistry 56, 445-449.

Guillon F, Amado R, Amaral-Collaço MT, Anderson H, Asp NG, Bach Knudsen KE, Champ M, Mathers J, Robertson JA, Rowland I \& Van Loo J (editor) (1998) Functional Properties of Non-Digestible Carbohydrates (PROFIBRE). European AIR Concerted Action AIR3CT94-2203. Nantes, France: INRA.

Haber GB, Heaton KW, Murphy D \& Burroughs LF (1977) Depletion and disruption of dietary fibres, effects on satiety, plasma glucose and serum insulin. Lancet ii, 679-682.

Health and Welfare Canada (1985) Report of the Expert Advisory Committee on Dietary Fibre. Ottawa, ON: National Health and Welfare.

Heaton KW (1990) Etiology of gallstones. In Dietary Fiber Chemistry, Physiology, and Health Effects [D Kritchevsky, C Bonfield and JW Anderson, editors]. New York: Plenum Press.

Hispley EH (1953) Dietary 'fibre' and pregnancy toxaemia. British Medical Journal 2, 420-422.

Hoebregs H (1997) Fructans in foods and food products, ionexchange chromatographic method: collaborative study. Journal of AOAC International 80, 1029-1037.

Jacobs DR Jr, Meyer KA, Kushi LH \& Folsom AR (1998) Wholegrain intake may reduce the risk of ischemic heart disease death in postmenopausal women: the Iowa Women's Health Study. American Journal of Clinical Nutrition 68, 248-257.

Jenkins DJA, Kendall CWC, Vuksan V, Vidgen E, Parker T, Faulkner D, Mehling CC, Garsetti M, Testolin G, Cunnane SC, Ryan MA \& Corey PN (2002) Soluble fiber intake approved by the US Food and Drug Administration for a claim of health benefits: serum lipid risk factors for cardiovascular disease assessed in a randomised controlled crossover trial. American Journal of Clinical Nutrition 75, 834-839.

Kolida S, Tuohy K \& Gibson GR (2002) Prebiotic effects of inulin and oligofructose. British Journal of Nutrition 87, Suppl. 2, S193-S197.

Lee SC \& Prosky L (1992) Dietary fiber analysis for nutrition labelling. Cereal Food World 37, 765-771.

Lee SC \& Prosky L (1995) International survey on dietary fiber: definition, analysis, and reference materials. Journal of AOAC International 78, 22-36.

Lee SC, Prosky L \& De Vries JW (1992) Determination of total, soluble, and insoluble dietary fiber in foods - enzymic-gravimetric method, MES-TRIS buffer: collaborative study. Journal of AOAC International 75, 395-416.

Lewis SJ \& Heaton KW (1997) The intestinal effects of bran-like plastic particles: is the concept of 'roughage' valid after all? European Journal of Gastroenterology and Hepatology 9, 553-557.

Liu S, Manson JE, Lee IM, Cole SR, Hennekens CH, Willett WC \& Buring JE (2000) Fruit and vegetable intake and risk of cardiovascular disease: the Women's Health Study. American Journal of Clinical Nutrition 72, 922-928.

Liu S, Stampfer MJ, Hu FB, Giovannucci E, Rimm E, Manson JE, Hennekens CH \& Willett WC (1999) Whole-grain consumption and risk of coronary heart disease: results from the nurses' health study. American Journal of Clinical Nutrition 70, 412-419.

McCleary B \& Prosky L (editors) (2001) Advanced Dietary Fibre Technology. Oxford, UK: Blackwell Science Ltd.

McCleary BV \& Codd R (1991) Measurement of (1-3)(1-4)- $\beta$-Dglucan in barley and oats: a streamlined enzymic procedure. Journal of the Science of Food and Agriculture 55, 303-312.

McCleary BV \& Monaghan DA (2002) Measurement of resistant starch. Journal of AOAC International 85, 665-675.

McCleary BV, Murphy A \& Mugford DC (2000) Measurement of total fructan in foods by enzymatic/spectrophotometric method: collaborative study. Journal of AOAC International $\mathbf{8 0}$, 571-579.
Mälkki Y \& Cummings JH (editors) (1996) COST Action 92 Dietary Fibre and Fermentation in the Colon. Proceedings of COST Action 92 workshop, Espoo, Finland, 15-17 June 1995. Brussels, Belgium: European Commission DGXII.

Marteau P, Flourié B, Cherbut C, Corrèze JL, Pellier P, Seylaz J \& Rambaud JC (1994) Digestibility and bulking effect of ispaghula husks in healthy humans. Gut 35, 1747-1752.

Meyer KA, Hushi LH, Jacobs DR, Slavin J, Sellers TA \& Folsom AR (2000) Carbohydrates, dietary fiber, and incident type 2 diabetes in older women. American Journal of Clinical Nutrition 71, 921-930.

Mongeau R \& Brassard R (1986) A rapid method for the determination of soluble and insoluble dietary fiber: comparison with AOAC total dietary fiber procedure and Englyst's method. Journal of Food Science 51, 1333-1336.

Mongeau R \& Brassard R (1990) Collaborative study of a rapid gravimetric method. Cereal Foods World 35, 319-324.

Olson BH, Anderson SM, Becker MP, Anderson JW, Hunninghake DB, Jenkins DJA, LaRosa JC, Rippe JM, Roberts DCK, Stoy DB, Summerbell CD, Truswell AS, Wolever TMS, Morris DH \& Fulgoni VL (1997) Psyllium-enriched cereals lower blood total cholesterol, but not HDL cholesterol, in hypercholesterolemic adults: results of a meta-analysis. Journal of Nutrition 127, 1973-1980.

Ouarne F, Guibert A, Brown D \& Bornet F (1999) A sensitive and reproducible analytical method to measure fructooligosaccharides in food products. In Complex Carbohydrates in Foods, pp. 191-201 [SS Cho, L Prosky and M Dreher, editors]. New York: Marcel Dekker Inc.

Pendlington AW, Meurée-Vanlaethem N \& Brookes A (1996) The method specific certification of the mass fraction of dietary fibre in lyophilised haricot beans, carrot, apple, full fat soya flour and bran breakfast cereal reference materials. CRMs 514, 515, 516, 517 \& 518. In BCR Information, Reference Materials [European Commission, editor]. Luxembourg: EUR-OP.

Pereira MA, Jacobs DR, Pins JJ, Raatz SK, Gross MD, Slavin JL \& Seaquist ER (2002) Effect of whole grains and insulin sensitivity in overweight hyperinsulinemic adults. American Journal of Clinical Nutrition 75, 848-855.

Perrin P, Pierre F, Patry Y, Champ M, Berreur M, Pradal G, Bornet F, Meflah K \& Ménanteau J (2001) Only fibres promoting a stable butyrate producing colonic ecosystem decrease the rate of aberrant crypt foci in rats. Gut 48, 53-61.

Pilch S (1987) Physiological Effects and Health Consequences of Dietary Fiber. Bethesda: Center for Food Safety and Applied Nutrition, FDA and Life Sciences Research Office, and FASEB.

Potter JD (1999) Fiber and colorectal cancer - where to now? New England Journal of Medicine 340, 223-224.

Prosky L, Asp NG, Schweizer TF, DeVries JW, Schweizer TF \& Harland BF (1985) Determination of total dietary fiber in foods and food products: collaborative study. Journal of the Association of Official Analytical Chemists 71, 1017-1023.

Salmeron J, Ascherio A, Rimm EB, Colditz GA, Spiegelman D, Jenkins DJ, Stampfer MJ, Wing AL \& Willett WC (1997a) Dietary fiber, glycemic load, and risk of NIDDM in men. Diabetes Care 20, 545-550.

Salmeron J, Manson JE, Stampfer MJ, Colditz GA, Wing AL \& Willett WC (1997b) Dietary fiber, glycemic load, and risk of non-insulin-dependent diabetes mellitus in women. Journal of the American Medical Association 277, 472-477.

Sandberg AS, Andersson H, Hallgren B, Hasselblad K \& Isaksson B (1981) Experimental model for in vivo determination of dietary fibre and its effect on the absorption of nutrients in the small intestine. British Journal of Nutrition 45, 283-294.

Schweizer TF, Walter E \& Venetz P (1988) Collaborative study for the enzymatic, gravimetric determination of total dietary fibre in foods. Mitteilungen aus der Gebiete der Lebensmitteluntersuchung und Hygiene 79, 57-68. 
Slavin JL (2000) Mechanisms for the impact of whole grain foods on cancer risk. Journal of the American College of Nutrition 19, Suppl. 3, 300S-307S.

Theander O, Aman P, Westerlund E, Andersson R \& Pettersson D (1995) Total dietary fiber determined as neutral sugar residues, uronic acid residues, and Klason lignin (the Uppsala method): collaborative study. Journal of AOAC International 78, 1030-1044.

Theander O, Aman P, Westerlund E \& Graham H (1994) Enzymatic/chemical analysis of dietary fiber. Journal of AOAC International 77, 703-709.

Trowell H (1972) Ischemic heart disease and dietary fiber. American Journal of Clinical Nutrition 25, 926-932.

Trowell H (1978) The development of the concept of dietary fiber in human nutrition. American Journal of Clinical Nutrition 31, Suppl. 10, 3-11.

Trowell H \& Burkitt D (1986) Medical aspects of nutrition. Physiological role of dietary fiber: a ten-year review. Boletin de la Asociacion Medica de Puerto Rico 78, 541-544.

Trowell H, Southgate DAT, Wolever TMS, Leeds AR, Gassull MA \& Jenkins DJA (1976) Dietary fibre redefined. Lancet i, 967.

Truswell AS (1999) Meta-analysis of the cholesterol-lowering effects of dietary fiber. American Journal of Clinical Nutrition 70, 942-943.

Truswell AS (2002) Cereal grains and coronary heart disease. European Journal of Clinical Nutrition 56, 1-14.
United States Food and Drug Administration (1999) Center for Food Safety and Applied Nutrition - A Food Labeling Guide. September 1994 (Editorial revisions June 1999). http://vm.cfsan.fda.gov/ dms/flg-toc.htm

Van Soest PJ \& Wine RH (1967) Use of detergents in the analysis of fibrous feeds. IV. Determination of plant cell walls constituents. Journal of AOAC International 50, 50-55.

Villettaz J-C, Amado R \& Neukom H (1981) Structural investigations of an arabinan from grape juice. Carbohydrate Polymers 1, 101-105.

Williams RD \& Olmsted W (1935) A biochemical method for determining indigestible residue (crude fibre) in faeces: lignin, cellulose and non-water soluble hemicelluloses. Journal of Biological Chemistry 108, 653-666.

Wolk A, Manson JE, Stampfer MJ, Colditz GA, Hu FB, Speizer FE, Hennekens CH \& Willett WC (1999) Long-term intake of dietary fiber and decreased risk in coronary heart disease among women. Journal of the American Medical Association 281, 1998-2004.

Wood R, Englyst HN, Southgate DAT \& Cummings JH (1993) Determination of dietary fibre. Collaborative trials. Part IV. A comparison of the Englyst and Prosky (AOAC) procedures for the determination of soluble, insoluble and dietary fibre. Journal of the Association of Public Analysts 29, 57-141.

World Health Organization (1990) Diet, nutrition, and the prevention of chronic diseases. World Health Organization Technical Report Series 797, 112. 